\title{
PROPIEDAD Y TRABAJO EN EL CONSTITUCIONALISMO DECIMONÓNICO FRANCÉS Y ESPAÑOL. ESTUDIO COMPARADO*.
}

\section{PROPERTY AND WORK ON FRENCH AND SPANISH 19TH CENTURY CONSTITUTIONALISM. A COMPARATIVE STUDY*.}

\author{
Isabel Ramos Vázquez \\ Universidad de Jaén
}

\begin{abstract}
SUMARIO: I.- INTRODUCCIÓN. II.- LOS DERECHOS DE PROPIEDAD Y TRABAJO EN LA FRANCIA DE PRINCIPIOS DEL SIGLO XIX: DE LA REVOLUCIÓN HASTA LA CONSTITUCIÓN DE $1830 . \quad$ III.- LA CONCEPTUALIZACIÓN JURÍDICA DE LA PROPIEDAD Y EL TRABAJO EN ESPAÑA: DE LA CONSTITUCIÓN DE 1812 AL CÓDIGO CIVIL DE 1889. IV.CUESTIÓN SOCIAL, REVOLUCIÓN DE 1848 Y "DROIT AU TRAVAIL" EN FRANCIA. V.- PROPIEDAD Y "REFORMA SOCIAL" EN LA ESPAÑA DE FINALES DE SIGLO XIX.
\end{abstract}

RESUMEN: Además de señalar la influencia francesa en el desarrollo del liberalismo y las ideas contractuales en las relaciones de trabajo desde la Revolución francesa hasta el final del siglo XIX, este estudio comparado sobre los orígenes de los conceptos de propiedad y trabajo en el constitucionalismo histórico francés y español, pretende contribuir a la comprensión del complejo proceso que se vivió en el terreno de las ideas antes de la emergencia del primer derecho obrero.

ABSTRACT: Apart from pointing out the French influence in the development of liberalism and contractual ideas of the employment relationships since the French Revolution until the end of the 19th century, this comparative study on the origins of property and labour concepts in French and Spanish historical constitutionalism, aims to contribute to the understanding of the convoluted process that took place in the inner of legal ideas before the emergence of labour law.

PALABRAS CLAVE: Propiedad, trabajo, liberalismo, Francia, España.

KEY WORDS: Property, labour, liberalism, France, Spain.

\section{I.- INTRODUCCIÓN.}

El liberalismo decimonónico consagró, entre los derechos de primera generación de los primeros textos constitucionales europeos, dos derechos individuales básicos: el derecho de libertad y el derecho de propiedad ("droit à la liberté" y "droit de propriété", en los originarios textos franceses). Ambos eran esenciales para activar un mercado libre, que acabara con la profunda crisis 
económica del Antiguo Régimen ${ }^{1}$, y aplicados a las relaciones de trabajo sirvieron para enajenarlas de las antiguas estructuras feudales o corporativas que lo habían tenido intervenido y apartado del mercado durante la Edad Moderna.

Para el pensamiento liberal original, el trabajo era la principal propiedad del hombre y una mercancía más de libre disposición en el mercado, adquiriendo con ello una nueva valoración positiva ${ }^{2}$. La dignificación del trabajo, y su consideración como el principal instrumento del hombre para la consecución de riqueza y prosperidad, pretendía acabar con los problemas del pauperismo y la vagancia, profundamente arraigados en los Estados europeos de finales del XVIII, pero al mismo tiempo alentó la defensa de un nuevo derecho: el derecho a trabajar o "droit de travailler", que no derecho al trabajo o "droit au travail", ni derecho del trabajo o "droit du travail", con connotaciones muy distintas 3 .

Ahora bien, lejos de positivizarse como tal en los primeros textos constitucionales, el derecho a trabajar se desarrolló a través de una serie de leyes que consagraron la libertad de trabajar ("liberté du travail'). Destacaron fundamentalmente entre ellas las leyes que se dictaron para la progresiva abolición de las relaciones feudales o de servidumbre a partir de los decretos del 4 de agosto de 1789 en Francia ${ }^{4}$, y del 6 de agosto de 1811 en España5; y las leyes dirigidas a la disolución del sistema gremial o cualquier otra forma de corporativismo de oficios, a partir del famoso edicto Turgot de 1776 o la ley Chapelier de 1791 en Francia ${ }^{6}$, o los distintos decretos de liberalización de oficios que se fueron dictando en España hasta la promulgación del decreto del Conde de Toreno de 1813, que suprimió todas las corporaciones gremiales o asociaciones de trabajadores, y que sería seguido de otras normas posteriores ${ }^{7}$.

\footnotetext{
* Este artículo se ha redactado como parte del Proyecto de Investigación "De la libertad de trabajo al nacimiento del derecho obrero. Estudio comparado del derecho español y francés durante el siglo XIX y principios del siglo XX" (UJA 2015/06/26), financiado por el Plan de Apoyo a la Investigación de la Universidad de Jaén.

1 Adam Smith, An Inquiry into the Nature and Causes of the Wealth of Nations (1776), trad. La riqueza de las naciones, libro I, capítulo X, Alianza, Madrid, 2011, pp.34 y ss.

2 John Locke, Second treatise of civil gobernment (1690), trad. Segundo tratado sobre el gobierno civil, capítulo 5 ${ }^{\circ}$ Altaya, Madrid, 1994, pp.55-57.

3 Michel Sonenscher, "The language of labour in revolutionary France", Movements populaires et conscience sociale, Paris, 1985, pp.564-570.

4 Henry Doniol, La Révolution française et la féodalité, Paris, 1876, Alphonse Aulard, La Révolution française et le régime féodal, París, 1919, o Jean Jacques Clere, "L'abolition des droits féodaux en France", Cahiers d'histoire. Revue d'histoire critique, 94-95 (2005), pp.135-157.

5 Salvador de Moxó, La disolución del régimen señorial en España, Madrid 1965, o Eduardo Galván Rodríguez, "La disolución del régimen señorial", Cortes y Constitución de Cádiz: 200 años, Madrid, 2011, vol.2, pp.204-219.

6 Edmond Soreau, "La loi Le Chapelier", Annales historiques de la révolution,tomo.VIII, 1931, pp.287-314, Thierry Muller-Hamon, "Aux origines de la suppression des corporations par la Révolution française: les conceptions de Guy-Charles Le Chapelier (père) sur la réforme des communautés de métier bretonnes à travers un mémoire inédit de 1782", Revue historique de droit français et étranger, 1996-1997, pp.525-559, Francine Soubiran-Paillet, "Nouvelle règles du jeu? Le decret d'Allarde et la loi Chapelier", Deux siécles de droit du travail, París, 1998, pp.17-24, o Steven L. Kaplan, La fin des corporations, Paris, 2001.
}

7 Gaspar Bayón Chacón, La autonomía de la voluntad en el Derecho del Trabajo. Limites a la libertad contractual en el Derecho histórico español, Madrid, 1955, pp.270-308, Antonio Álvarez 
Estas leyes pretendian eliminar las trabas que gran parte de la población en el Antiguo Régimen tenía al trabajo. Pero, al mismo tiempo que se relacionó con la salida de la crisis económica, y con la necesidad de apartar a gran parte de la población del pauperismo y la vagancia, el derecho a trabajar que esgrimía el pensamiento liberal se conectó también íntimamente con un nuevo concepto de mercado ("marché"), que no sólo era económico sino también social y político.

La sociedad de mercado ("société de marché") a la que se vinculó la libertad de trabajo y el trabajo considerado como propiedad en el primer liberalismo, se basaba en la "utopía" de la autorregulación o, en palabras de Fernand Tangue, en "le fantasme d'une société caractérisée par l'autoregulation spontanée ainsi que par l'absence de conflits ou de division sociale, l'une expliquant en l'occurrence l'autre"8. En el mercado ideal de los liberales, el libre juego de la oferta y la demanda autorregularía las relaciones de trabajo sin necesidad de ninguna intervención estatal. Los patronos o propietarios del capital, y los trabajadores o propietarios de la fuerza de trabajo, se pondrían de acuerdo en las condiciones de trabajo en el marco jurídico de la autonomía de la voluntad de las partes.

Las consecuencias negativas de esta "utopía liberal" no se hicieron esperar. La "cuestión social" ("question sociale") fue el término que comenzó a acuñarse ya en los primeros decenios del siglo XIX en los ambientes fourieristas de Francia, y que no tardó en llegar a España en la década de los treinta, para poner de relieve los problemas sociales derivados de la nueva división entre capital y trabajo ${ }^{9}$.

En este momento, cuando el fenómeno de la pobreza tradicional comenzaba a adquirir nuevas connotaciones sociales alejadas de la mera caridad, y el primer liberalismo individualista representado por el "laissez faire, laissez passer" dejaba de ser suficiente para solucionar los problemas derivados de las nuevas relaciones de trabajo, algunas voces empezaron a modificar el discurso politico y jurídico sobre la propiedad y el trabajo para que la maquinaria del Estado liberal no se resintiera en su conjunto. Este artículo pretende analizar tales cambios conceptuales en Francia y en España, muy cercanas tanto geográfica como doctrinalmente, y su reflejo en los principales textos constitucionales que se promulgaron durante el siglo XIX en ambos países.

\footnotetext{
Montero, "La libertad de trabajo en el entorno normativo de las Cortes de Cádiz", Sobre un hito jurídico: La Constitución de 1812, Jaén, 2012, pp.325-341, José Antonio Yvorra Limorte, "La libertad de industria en las Cortes de Cádiz", Las Cortes de Cádiz, la Constitución de 1812 y las independencias nacionales en América, 2011, pp.265-279, o Eduardo Morales Solchaga, "La Constitución de Cádiz y la disolución de los gremios: el caso de los plateros pamploneses", Principe de Viana, n²56 (2012), pp.761-781.

8 Fernand Tangue, Le droit au travail entre histoire et utopie. 1789-1848-1989: de la répression de la mendicité à l'allocation universelle, Bruxelles, 1989, p.11.

9 Ferdinand Tönnies, Desarrollo de la cuestión social, Barcelona, 1927, y Gonzalo Capellán de Miguel, "Cambio conceptual y cambio histórico. Del pauperismo a la "cuestión social", Historia Contemporánea, 29 (2005), pp.539-590.
} 


\section{II.- LOS DERECHOS DE PROPIEDAD Y TRABAJO EN LA FRANCIA DE PRINCIPIOS DEL SIGLO XIX: DE LA REVOLUCIÓN HASTA LA CONSTITUCIÓN DE 1830.}

El primer texto promulgado por la Asamblea Nacional francesa en plena época revolucionaria, la Déclaration des droits de l'homme et du citoyen, aprobada el 26 de agosto de 1789, ya se hacía eco del mensaje liberal individualista a través de la enconada defensa de los derechos de libertad y propiedad que hacian sus artículos 2, 4 y 17, fundamentalmente. Este mismo mensaje se trasladó a la primera Constitución francesa de 1791, de carácter monárquico y en cuyo preámbulo se recogieron aquellos; y también a la Constitución de la Primera República francesa de 1793, que aún acercó más la definición de la propiedad a la de trabajo, afirmando en su artículo 16 que "le droit de propriété est celui qui appartient à tout citoyen de jouir et de disposer à son gré de ses biens, de ses revenus, du fruit de son travail et de son industrie".

La definición del trabajo como propiedad que se desprende del citado artículo, estaba, sin duda, en consonancia con la de la filosofia iusnaturalista y liberal clásica de Smith, Hobbes, Pufendorf o Locke10, desarrollada fundamentalmente en Francia por pensadores como Jean-Baptiste Say (principal difusor de las ideas económicas de Adam Smith), Quesnay, Turgot, Montesquieu o Voltaire, con alguna variante ${ }^{11}$. Coetáneos a ellos, a finales del siglo XVIII también consideraron el trabajo desde una primigenia perspectiva socialista y mucho más idealizada, los filósofos Étienne-Gabriel Morelly y Léger Marie Deschamps, que entroncaban con las propuestas utópicas de Thomas More y pueden considerarse precursores de las posteriores ideas socialistas de Cabet, Fourier o Saint-Simon ${ }^{12}$.

Sin embargo, las ideas que entonces calaron en la opinión pública y se plasmaron en los primeros textos de la Revolución, fueron las propias del liberalismo económico y el liberalismo jurídico, de corte individualista y burgués (la "utopía liberal"), y no las que proponian sociedades perfectas desde una perspectiva absolutamente idealizada que muy pocos compartian (la "utopía socialista"). La nueva sociedad burguesa que trataba de erigirse tras los acontecimientos revolucionarios, era una sociedad capitalista que entendió el trabajo como la propiedad más sagrada del hombre, el modo de vida que le daba la Naturaleza y su principal medio de progreso, haciendo con ello una lectura correctora de las diferencias estamentales propias del Antiguo Régimen: "Un homme n'est pas pauvre parce qu'il n'a rien, mais parce qu'il ne travaille pas"13.

10 Crawford Brough Macpherson, La Théorie politique de l'individualisme possessif de Hobbes à Locke, trad. M. Fuchs, Gallimard, Paris, 1971, o James Tully, Locke. Droit naturel et propriété, trad. C. J. Hutner, P.U.F., Paris, 1992.

11 Reinhard Bach, "Rousseau et les Physiocrates: une cohabitation contradictoire", Rousseau: économie politique, Etudes Jean-Jacques Rousseau, vol. XI, 1999, pp. 9-82, y Céline Spector, "Variations de la propriété: Montesquieu contre l'individualisme possessif", Inventions et critiques du libéralisme. Le pouvoir, la personne, la propriété, Lyon, 2008, pp.95-116.

12 Charles Rappoport, Le Socialisme III. Le Socialisme au XVIIIe siècle. Morelly, París, 1921, Walter Bernardi, Morelly y Dom Deschamps. Utopía e ideología en la época de la Ilustración. Florencia, 1979, o Jean Bart, "De la contrainte au plaisir. Le travail chez Morelly et Dom Deschamps", Du droit du travail aux droits de l'humanité, Rennes, 2003, pp.35-46.

13 Barón de Montesquieu, L'Esprit des lois, Genève, 1748, XXIII, p.29. 
En palabras de Voltaire, con el triunfo de la propiedad y la libertad "tous les paysans ne seront pas riches; et il ne faut pas qu'ils le soient. On a besoin d'hommes qui n'aient que leurs bras et de la bonne volonté. Mais ces hommes (...) seront libres de vendre leur travail à qui voudra le mieux payer. Cette liberté leur tiendra lieu de propriété. L'espérance certaine d'un juste salaire les soutiendra. Ils élèveront avec gaieté leurs familles dans leurs métiers laborieux et utiles"14.

La propiedad como un derecho natural básico por ser medio de subsistencia y conservación de la humanidad, y la consecuente imagen enaltecida del trabajo que hacía libre al hombre, se impusieron así en el discurso jurídico y económico de la Francia revolucionaria ${ }^{15}$. En este contexto, el derecho a trabajar o "droit de travailler" se entendió como un presupuesto libertador del pueblo, idealizado y carente de cualquier connotación social, como podemos ver con meridiana claridad en el preámbulo del edicto de Turgot: "Nous nous hâtons de rejeter une pareille maxime. Dieu, en donnant à l'homme des besoins, en lui rendant nécessaire la ressource du travail, a fait du droit de travailler la propriété de tout homme et cette propriété est la première, la plus sacrée et la plus imprescriptible de toutes"16.

La Constitución de 1795 perdió el impulso revolucionario, pero no la concepción liberal de la propiedad individual y el trabajo. Alejada ya del simbolismo de las palabras o el discurso grandilocuente, los anteriormente considerados "derechos naturales y sagrados" de la filosofia iusnaturalista liberal, se consolidaron en este texto como los derechos del hombre en la sociedad, es decir, como derechos civiles ${ }^{17}$.

Por ese motivo, aunque la definición del derecho de propiedad de su artículo 5 varió poco frente a la del texto anterior ("la propriété est le droit de jouir et de disposer de ses biens, de ses revenus, du fruit de son travail et de son industrie'), cuando seguidamente esta norma fundamental hizo una novedosa relación de los correlativos deberes que tenía la sociedad para la conservación de sus derechos, estableció en el artículo 8 el deber de mantener las propiedades sobre las que se basaba (el cultivo de la tierra, todas las producciones, todos los medios de trabajo, y todo el orden social): "c'est sur le maintien des propriétés que reposent (la culture des terres, toutes les productions, tout moyen de travail, et tout l'ordre social)".

Con el establecimiento de este deber, se produjo una evolución desde la filosofia iusnaturalista revolucionaria al nuevo orden liberal burgués, cuyo objetivo fundamental ya no era la defensa de los derechos naturales o inalienables del hombre, sino la conservación de la república y el orden establecido. Pero, en lo que respecta a la consideración individualista del trabajo,

14 Voltaire, "Questions sur 1'Encyclopçedie. Article Propriété" (1771), Oeuvres de Voltaire, t.32, Paris, 1829, p.21.

15 Entre otros, Lemercier de la Rivière, L'Ordre naturel et essentiel des sociétés politiques (1767), Fayard, Paris, 2001, pp.24-35, Anne Robert Jacques Turgot, Réflexions sur la formation et la distribution des richesses, París, 1776, cap.V y ss, o Jean Antoine Nicolas de Caritat Condorcet, Arithmétique politique. Textes rares ou inédits (1767-1789), Paris, 1994, pp.56-61

16 Alfred Franklin, Dictionnaire des arts, métiers et professions, Paris, 1906, p.293.

17 Florence Gauthier, Triomphe et mort du droit naturel en Révolution-1789-1795-1802, PUF, Paris, 1992. 
esto no implicó ningún cambio. Antes al contrario, la moderación del discurso liberal o "doctrinarismo" que más adelante se consolidó durante la época napoleónica, mantuvo como presupuestos básicos del nuevo régimen liberal burgués la defensa del individualismo, la libertad civil y la propiedad.

El hecho de que los textos fundamentales de 1799, 1802 y 1804, que fueron concentrando el poder en Napoleón Bonaparte hasta la constitución del Imperio, fueran meros textos orgánicos y no incorporaran expresamente ninguno de los derechos de la Declaración de Derechos del Hombre y del Ciudadano, no quiere decir que no compartieran estos principios de libertad y propiedad. Excluidos del texto constitucional, simplemente se prefirió dejar el desarrollo de los derechos civiles básicos del moderantismo al texto de naturaleza inmediatamente inferior, el Código civil napoleónico de 1804, que se convirtió a partir de ese momento en el principal referente del orden liberal burgués en Europa, y supuso el instrumento técnico del que se valió el racionalismo liberal doctrinario para la transformación de la razón jurídica en ley escrita, es decir, para positivización del derecho más allá de cualquier filosofia ${ }^{18}$.

El Code Civil de 1804, popularmente conocido como el Código de Napoleón, fue redactado por una comisión de cuatro juristas, François Denis Tronchet, Félix-Julien-Jean Bigot de Préameneu, Jean-Étienne-Marie Portalis y Jacques de Maleville, bajo la dirección de Jean Jacques Régis de Cambacérès ${ }^{19}$, quien años atrás ya se había referido a la propiedad como un derecho sagrado ("les propriétés doivent être sacrées: loin de nous ces systèmes dictés par l'immoralité et la paresse, qui atténuent l'horreur du larcin et l'érigent en doctrine' $)^{20}$.

Esta concepción absoluta del derecho de propiedad fue la que se impuso en el Código, fundamentalmente mediante la redacción del artículo 544: "La propriété est le droit de jouir et disposer des biens de la manière la plus absolue, pourvu que'on n'en fasse pas un usage prohibé par les lois ou par les règlements".

Al defender el contenido de este artículo ante la Asamblea francesa, Tronchet aseguraba que "le droit de propriété est celui qu'un individu peut avoir d'appliquer exclusivement à son bien-être personnel, une telle portion du sol, une telle portion des fruits qu'il produit naturellement ou artificiellement, tel ou tel effet mobilier que la nature a créé ou reproduit, ou que l'industrie de l'homme a elle-même formé avec les matériaux que la nature avait mis à sa disposition"21.

18 Philippe Sagnac, , La législation civile de la Révolution française (1789-1804). Essai d'histoire sociale, Paris, 1898, réimpression 1971, François Ewald (dir.), Naissance du Code civil, Paris, 1989, Jean-Louis Halperin, L’impossible Code civil, PUF, Paris, 1992, Xavier Martin, Mythologie du Code Napoléon, Bouère, 2003, Jean-Louis Halperin, Le code civil, 2e éd., Dalloz, París, 2003, JeanFrançois Niort, Homo Civilis. Contribution à l'histoire du Code civil français. Tome I et II, Presses universitaires d'Aix-Marseille, 2004, o Philippe Jouary, "La lésion dans le Code civil de 1804. Études sur l'influence du libéralisme économique sur le Code civil", Droits, 2005, pp.103-122

19 Jean Jacques Régis de Cambacérès, Mémoires inédits. Éclaircissements publiés par Cambacérès sur les principaux événements de sa vie politique, Paris, 1999, Laurence Chatel de Brancion, Cambacérès: maître d'oeuvre de Napoléon, Perrin, Paris, 2001, o Jean Hilaire, "Cambacérès et le Code Civil", Bulletin Academie des Sciences et Lettres de Montpellier, n ${ }^{\circ} 38$ (2007), pp.61-68.

20 Jean Jacques Régis de Cambacérès, Bulletin des Lois de la République française, nº70, p.4.

21 Cfr. Xavier Martin, Nature humaine et Révolution française. Du Siècle des Lumières au Code Napoléon, Bouère, 2001, p.262. 
De tal manera, el derecho de propiedad no sólo se sacralizaba y se convertía en un derecho "absoluto" ("absolue') del individuo, sino que también se consolidaba su conceptualización como derecho civil y no como derecho natural, que debía disfrutarse en atención a lo dispuesto por las leyes o reglamentos, según indicaba la propia norma.

Otro cambio importante que puede observarse, si se atiende a la redacción del artículo y la definición de Tronchet, fue que el derecho de propiedad adquirió nueva connotación eminentemente material y se convirtió fundamentalmente en la propiedad de los bienes, separando y elevando la figura del propietario de los mismos del que sólo poseía su fuerza de trabajo. La obligación de respeto por parte del resto de la sociedad que conllevaba la nueva definición del derecho (teoría de la ocupación), excluyó del mismo la propiedad sobre las actividades individuales de trabajo (teoria del trabajo), e hizo necesaria la concurrencia de un elemento material en el que plasmarse (tierras, medios de producción, instrumentos o materiales de trabajo...). Esta idea se heredaría posteriormente en la Constitución de 1814, y en la Constitución de 1830 que impuso la monarquía constitucional de Luis Felipe de Orleans hasta que la Revolución de 1848 precipitara la Segunda República Francesa ${ }^{22}$.

El propietario (el "homo economicus" de Adam Smith o el "ciudadano" de estas primeras Constituciones), se convirtió así en la pieza angular del ordenamiento jurídico liberal, adquiriendo a través del derecho de propiedad una potestad unitaria, perpetua y absoluta, estrictamente vinculada a su libertad. La propiedad era, en ese sentido, el derecho principal o nuclear de todo el ordenamiento, o, en palabras de Portallis, "l'âme universelle de toute la législation": "La plus précieuse maxime d'un Code civil, la première, comme la plus importante de ses dispositions, est (...) celle qui proclame le droit de propriété: toutes les autres n'en sont que les suites ou les conséquences'23.

Por su parte, la libertad de trabajo ("liberté du travail") se vio desarrollada en el Código napoleónico a través del principio de la libertad de contratación entre patrono y trabajador, o principio de autonomia de la voluntad de las partes. El instrumento jurídico elegido para ello fue el antiguo contrato civil romano del arrendamiento de servicios, la locatio conductio ${ }^{24}$, reelaborado por los redactores del Código en la figura del louage d'ouvrage siguiendo fundamentalmente la doctrina de Robert Joseph Pothier25.

22 Arts. 9 y 10 de la Constitución de la primera Restauración, de 4 de junio de 1814 , y arts. 8 y 9 de la Constitución monárquica de 14 de agosto de 1830.

${ }^{23}$ Cfr. Xavier Martin, Nature humaine et Révolution française. Du Siècle des Lumières au Code Napoléon, op. cit., pp.264-265.

24 Sobre la importancia del derecho romano como fuente del Código civil de 1804, Alfred Bertauld, Introduction à l'histoire des sources du Droit français, París 1860, pp.I-II, y más recientemente André-Jean Arnaud, Les origines doctrinales du Code civil français, París, 1969, Xavier Martin, "Aux sources thermidoriennes du Code civil. Contribution à une histoire politique du droit privé", Droits, 1987, pp.107-116, Victor Lasserre-Kiesow, "L'esprit scientifique du Code civil", Droits, 2005, pp.53-67, o Jean-Louis Thireau, "Fondements romains et fondements coutumiers du Code civil", Droits, 2006, pp. 3-18.

25 Robert Joseph Pothier, Pandectae Justinianeae, in novum ordinem digestae: cum legibus Codicis, et Novellis, quae Jus Pandectarum confirmant, explicant, aut abrogant. I. Prolegomena seu 
El arrendamiento de obra o "louage des ouvrages", se reguló en el Libro III junto con el arrendamiento de cosas o "louage des choses", asumiéndose con ello la naturaleza dual clásica heredada de la doctrina iusromanista ${ }^{26}$. El artículo 1710 definía expresamente el arrendamiento de obra, estableciendo que "le louage d'ouvrage est un contrat par lequel l'une des parties s'engage à faire quelque chose pour J'autre, moyennant un prix convenu entre elles".

Se establecieron tres tipos básicos de este contrato en el artículo 1779: el arrendamiento de trabajadores domésticos o criados, el de conductores por tierra o por agua, y el de contratistas de obras por cotización o mercado ${ }^{27}$. En cualquier caso, según quedó establecido en el artículo 1780, "on ne peut engager ses services qu'à temps, ou pour une entreprise déterminée".

Esta disposición era de fundamental importancia para consolidar en el Código el principio de la libertad de trabajo, frente al trabajo esclavista o servil de épocas anteriores. Así lo señalaron juristas como Maleville, Locré, Mouricault ${ }^{28}$, o Troplong, quien afirmaría que "nous avons vu le lègislateur considérer le travail de l'homme comme un capital commercial", tratando de separar este nuevo trabajo libre en el mercado de cualquier otro tipo de trabajo dependiente o vinculado ${ }^{29}$.

Al margen de ello, el brevísimo articulado del Código solo se pronunció sobre la necesidad de salario o precio del arrendamiento, estableciendo que en caso de duda era el maestro o patrono quien debía ser creído sobre el mismo, y dejó cualquier otra cuestión relativa a la prestación del trabajo a la autonomía de la voluntad de las partes. A la obra de Pothier, que seguía siendo el principal referente sobre el tema, comenzaron a sumarse otras aportaciones que trataron de arrojar mayor luz sobre un contrato que, si era residual o muy secundario en el derecho romano y el posterior derecho bajomedieval y moderno, se había convertido en el único instrumento jurídico para dar respuesta a cualquier tipo de trabajo asalariado en el régimen liberali30. Aún así, definido fundamentalmente

praefationem, et viginti-duos priores libros, Lugduni, 1782, p.533, y Robert Joseph Pothier, Traité du contrat de louage, Paris-Orléans, 1778.

26 Louis Vincent Guillouard, Traité du contrat de louage. Livre III, titre VIII, du Code Civil. II. Articles 1752 à 1831, vol.1, París, 1887, p.7

27 Art. 1779 Code Civil 1804: "ll y a trois espèces principales de louage d'ouvrage et d'industrie: $1^{\circ}$. Le louage des gens de travail qui s'engagent au service de quelqu'un; $2^{\circ}$. Celui des voituriers, tant par terre que par eau, qui se chargent du transport des personnes ou des marchandises $3 .^{\circ}$ Celui des entrepreneurs d'ouvrages par suite de devis ou marchés".

28 Jacques de Maleville, Analyse raisonnée de la discussion du Code civil au Conseil d'État, Librairie de la Cour de Cassation (Paris, 1805), 3e éd. París, 1822, vol.III, p.401, Jean Guillaume baron Locré, Législation civile, commerciale et criminelle. Commentaire et complément des Codes Français, tome septième, Bruxelles, 1836, pp.168-171, Thomas Laurent Mouricault, Rapport fait par Mouricault, au nom de la section de législation, sur le projet de loi concernant le contrat de louage, et formant le titre XIII du livre III du Code civil, Paris, Séance du 14 ventôse an XII., pp.2123

29 Raymond Théodore Troplong, Le Droit civil expliqué selon l'ordre des articles du Code. De l'echange et du louage, Bruxelles, 1841, p.225.

30 Por ejemplo, Philippe-Antoine Merlin de Douai, Répertoire universel et raisonné de jurisprudence, 4e éd., París, 1812, vol.7, bajo la voz louage, pp.165 y ss, Charles Bonaventure Marie Toullier y Jean Baptiste Duvergier, Le droit civil français, suivant liorder du Code, tomo 3, París, 1836, pp.93 y ss, Jean Baptiste Duvergier, "Des caractères distinctifs du louage d'ouvrage et du mandat salarié", Revue de Législation et de Jurisprudence (April-September 1837), pp.60-77, 
como un contrato consensual, y generalmente de carácter oral, en el libre juego de la oferta y la demanda el trabajador o "propietario del trabajo" resultó sin duda alguna la parte más débil frente al patrón o "propietario del capital".

\section{III.- LA CONCEPTUALIZACIÓN JURÍDICA DE LA PROPIEDAD Y EL TRABAJO EN ESPAÑA: DE LA CONSTITUCIÓN DE 1812 AL CódIGO CIVIL DE 1889.}

En España, la Riqueza de las naciones de Adam Smith ya se había traducido al castellano a la altura de 179431 ; y la imagen idealizada de la propiedad como un derecho natural básico para la subsistencia de la humanidad, así como la consideración del trabajo como una de sus manifestaciones más sagradas, propias del pensamiento iusnaturalista, también fueron ampliamente difundidas a finales del siglo XVIII por autores como Campomanes ${ }^{32}$, Ward $^{33}$, Foronda ${ }^{34}$, Capmany ${ }^{35}$, o Jovellanos ${ }^{36}$, quien afirmara, por ejemplo: "El hombre debe vivir de los productos de su trabajo (...). De este principio se deriva el derecho que tiene todo hombre á trabajar para vivir; derecho absoluto, que abraza todas las ocupaciones útiles, $y$ tiene tanta extensión como el de vivir y conservarse. Por consiguiente, poner limites á este derecho, es defraudar la propiedad más sagrada del hombre, la más inherente á su ser, la más necesaria para su conservación"37.

Esta dignificación del trabajo como propiedad o mercancía básica para impulsar el mercado libre, y la defensa del derecho a trabajar de todo hombre, permitieron su progresiva liberalización, con el fin de las relaciones señoriales y las corporaciones gremiales, y con la aparición de un buen número de decretos que reconocían libertades económicas o de industria desde finales del siglo XVIII hasta la proclamación de la primera Constitución española de 1812 en las Cortes de Cádiz. Sin embargo, a la hora de positivizar los derechos fundamentales en este primer texto constitucional, la imagen idealizada de la propiedad y del

Raymond Théodore Troplong, Le Droit civil expliqué selon l'ordre des articles du Code. De l'echange et du louage, Bruxelles, 1841, pp.225 y ss, Charles Demolombe, Cours de Code Napoléon, París, 1804-1878, vols.36 y 37, o Louis Vincent Guillouard, Traité du contrat de louage. Livre III, titre VIII, du Code Civil. II. Articles 1752 à 1831, París, 1887,

31 Josef Alonso Ortiz, Investigación de la naturaleza y causas de la Riqueza de las naciones, obra escrita en inglés por Adam Smith, Valladolid, 1794.

32 Pedro Rodríguez de Campomanes, Discurso sobre la educación popular de los artesanos y su fomento, Madrid, 1775.

33 Bernardo Ward., Proyecto económico en que se promueven varias providencias dirigidas a promover los intereses de España con los medios y fondos necesarios para su planificación, Madrid, 1779.

34 Valentín de Foronda, Cartas sobre los asuntos más exquisitos de la economía politica, y sobre las leyes criminales, Madrid, 1789.

35 Antoni de Capmany, Discurso económico-politico en defensa del trabajo mecánico de los menestrales, y de la influencia de sus gremios en las costumbres populares, conservación de las artes, $y$ honor de los artesanos, Madrid y Barcelona, 1778.

36 Gaspar Melchor de Jovellanos, Informe dado á la Junta General de Comercio y Moneda sobre el libre ejercicio de las Artes por Gaspar Melchor de Jovellanos, Madrid, 1785.

37 Gaspar Melchor de Jovellanos, Informe dado á la Junta General de Comercio y Moneda sobre el libre ejercicio de las artes, Madrid, 1785, pp.4-5. 
trabajo trocó en una imagen mucho más racional o ajustada a su objetivo legislativo: la protección y defensa del nuevo orden burgués.

A diferencia de las primeras Constituciones revolucionarias francesas, precedidas de la tabla o declaración de derechos del hombre, la Constitución española de 1812 adoleció conscientemente de una parte dogmática o declaración de derechos. En parte, porque la intención de los legisladores fue presentarla como un texto propio, fruto de la tradición, de cara a los absolutistas representados en las Cortes de Cádiz. Y en parte también porque, frente al modelo idealista francés, en la Constitución de 1812 no quisieron reconocerse los derechos individuales como derechos los naturales propios de la filosofia iusnaturalista, que se predicaban del hombre en abstracto, sino como derechos civiles o realidades jurídicamente reconocidas al nacional español, en defensa de los intereses de la nueva clase burguesa que estaba construyendo el régimen liberal ${ }^{38}$.

Coincidiendo con la evolución que ya se había producido en este sentido en Francia durante la última fase de la etapa republicana y la era napoleónica, el derecho de propiedad que se reconoció en la Constitución española de 1812 fue, en consecuencia, un derecho absoluto, individual y básico, incluso "sagrado"; pero no natural, sino civil, y de carácter material, o lo que es lo mismo, alejado de cualquier connotación relativa a la actividad individual del trabajo. Así aparece reconocido, aunque no se defina, de manera directa en el artículo 4 de la Constitución ("la Nación está obligada a conservar y proteger por leyes sabias y justas la libertad civil, la propiedad y los demás derechos legitimos de todos los individuos que la componen"), y, de manera indirecta, en el artículo 172.10 ("no puede el Rey tomar la propiedad de ningún particular ni corporación, ni turbarle en la posesión, uso y aprovechamiento de ella").

La propiedad a la que estaba aludiendo el texto constitucional era una propiedad material, que se podía ocupar o tomar (teoría de la ocupación frente a la teoría del trabajo). Esto no se discutió durante los debates parlamentarios que precedieron a la aprobación del artículo cuarto ${ }^{39}$, aunque se entendía implícitamente en el discurso. Cuando Agustín de Argüelles hablaba de propiedad, se refería a la "propiedad territorial o la industrial" 40 , y cuando se hablaba de "propietarios" se hacía referencia sin ninguna duda a quienes poseían un cierto nivel de renta, los verdaderos "ciudadanos".

Este concepto del derecho de propiedad, absoluto, individual y material, se reforzaría en los sucesivos textos constitucionales decimonónicos, desde el Estatuto Real de 1834 a la Constitución de 1876, quedando finalmente definido en el artículo 348 del Código Civil español de 1889 de la siguiente manera: "La propiedad es el derecho de gozar y disponer de una cosa sin más limitaciones que las establecidas en las leyes".

38 Bartolomé Clavero, Evolución histórica del constitucionalismo español, Madrid, 1986, p.39.

39 Diario de Sesiones de las Cortes Generales y Extraordinarias, $n^{\circ} 332$, de 30 de agosto de 1811, pp.1729-1731.

40 Agustín de Argüelles, Discurso preliminar a la Constitución de 1812, ed. Centro de Estudios Constitucionales, Madrid, 2011, p.85. 
Por consiguiente, del discurso que se impuso en las Cortes de Cádiz y se mantuvo durante todo el constitucionalismo decimonónico, se desterró toda referencia a la idea de trabajo como propiedad. De hecho, en el primer modelo constitucional español, el trabajo libre (frente a la esclavitud colonial, que se mantuvo) quedó representado como una suerte de relación "cuasi-domestica" o "cuasi-dominical"41, muy alejado de la imagen idealista o utópica del mismo que proponía la filosofia iusnaturalista de primer liberalismo o liberalismo radical. El texto de Cádiz hablaba de "propietarios" o amos, y de "sirvientes" (término que expresamente se utiliza en al artículo 25 para excluirlos del concepto de ciudadania) ${ }^{42}$; y esta fue la herencia que recogieron las Constituciones españolas posteriores hasta la Constitución de 1876, y los primeros proyectos de Código Civil español, a los que se dejó el desarrollo de la cuestión ${ }^{43}$.

En atención a estas ideas, los primeros proyectos de Código civil español, el proyecto de 1821 y el proyecto de 1836, regularon el trabajo en el ámbito del derecho de las personas y no en el derecho de obligaciones o contratos, a través de la figura del arrendamiento de obra o servicio (la antigua locatio conductio romana o el louage d'ouvrage francés) ${ }^{44}$. Concretamente, el proyecto de 1821 situaba esta figura en el libro "De los derechos y obligaciones con respecto a las personas según su diferente condición doméstica", que también incluía las relaciones matrimonial, paterno-filial y de guarda de menores e incapacitados. El título dedicado a este tipo de arrendamiento de obra o servicio llevaba por título "De la condición de superior y dependiente", lo que refuerza esa idea de su naturaleza "cuasi-doméstica" o "cuasi-dominical" de la que ya hablaba Alonso Olea ${ }^{45}$.

La situación comenzó a cambiar debido a la influencia francesa ${ }^{46}$, y a voces patrias como las de Cirilo Álvarez Martínez, José M $M^{a}$ Fernández de la Hoz, o Pedro Gómez de la Serna y Juan Manuel Montalbán ${ }^{47}$, que señalaron la creciente

41 Manuel Alonso Olea, De la servidumbre al contrato de trabajo, $2^{\circ}$ edic. Madrid, 1987, p.12 y pp. 175-176.

42 Carlos Petit, "Amos, sirvientes y comerciantes. Algo más sobre el primer modelo constitucional", Derecho Privado y revolución burguesa, Derecho privado y revolución burguesa: II Seminario de Historia del Derecho Privado, Gerona, 1990, pp.87-122.

43 Bartolomé Clavero, La propiedad considerada como capital, 1987, y Mario Bedera Bravo, "La propiedad privada como elaboración del liberalismo burgués. Su proceso de positivación", Anales de Estudios Económicos y Empresariales, n5 (1990), pp.263-286.

${ }^{44}$ Isabel Ramos Vázquez, "Marco jurídico de las relaciones de trabajo en el siglo XIX. Del antecedente de locatio conductio, la influencia del louage d'ouvrage et d'industrie, hasta el arrendamiento de obras y servicios", Anuario de Historia del Derecho Español, tomo LXXXVI (2016), pp.547-574.

45 Manuel Alonso Olea, De la servidumbre al contrato de trabajo, op. cit., p.12 y pp.175-176.

46 Juan Baró Pazos, La codificación del Derecho civil en España (1808-1889), Santander, 1992, pp.67-83, Manuel J. Peláez Albendea, "Le Code de 1804, le Code civil espagnol de 1889 et le principe de la liberté" Le Code civil et les droits de l'homme, París, 2005, pp.309-317, Adela Mora Cañada, "En los comienzos de la codificación civil española", Forum historiae iuris (2005), o Juan Baró Pazos, "La influencia del Código civil francés (1804) en el Código civil español (1889)", La codificación española. Una aproximación doctrinal e historiográfica a sus influencias extranjeras, y a la francesa en particular, Madrid, 2014, pp.53-128

47 Cirilo Álvarez Martínez, Instituciones de derecho civil, Valladolid, 1840, p.268, José $\mathrm{M}^{\mathrm{a}}$ Fernández de la Hoz, Código civil redactado con arreglo a la legislación, Madrid, 1843, pp.207-208, 
importancia de este tipo de contratos en el nuevo mercado de trabajo liberal, y consiguieron finalmente que en el siguiente proyecto de Código civil de 1851, el contrato de arrendamiento de servicios se trasladara desde el derecho de las personas al derecho de obligaciones y $\operatorname{contratos}^{48}$, donde quedó definitivamente ubicado en el Código civil español de $1889^{49}$.

El Código civil español de 1889, participaba de la misma teoría dual de la locatio conductio romana que había calado en la ley y la doctrina francesa 50 , entendiendo que "dentro de este concepto legal tiene cabida tanto la locatio operarum como la locatio operis del derecho romano"51; y señalaba el carácter temporal del contrato en el artículo 1583 ("puede contratarse esta clase de servicios sin tiempo fijo, por cierto tiempo, o para una obra determinada. El arrendamiento hecho para toda la vida es nulo"). Además, también como en el Código francés, distinguía tres tipos fundamentales de arrendamiento de obras y servicios: el de criados y trabajadores asalariados (arts.1583-1587), el de obras por ajuste o precio alzado (arts.1588-1600), y el de transportes por agua y tierra, tanto de personas como de cosas (arts.1601-1603). Pero poco más añadía en los escasos artículos que dedicaba a esta clase de contrato de arrendamiento, en los que apenas se reguló en materia de credibilidad sobre el salario o despido ${ }^{52}$.

Esta situación de vacío legal, dejó a los trabajadores, proletarios o jornaleros, absolutamente desamparados frente a las condiciones de trabajo impuestas por los propietarios también en España, y acució, como en Francia, la aparición de los primeros problemas relacionados con la llamada "cuestión social".

\section{IV.- CUESTIÓN SOCIAL, REVOLUCIÓN DE 1848 Y "DROIT AU TRAVAIL" EN FRANCIA.}

Como se ha señalado en la introducción, la "cuestión social" ("question sociale") fue el término que comenzó a acuñarse ya en los primeros decenios del siglo XIX en los ambientes fourieristas de Francia para referirse a los problemas

o Pedro Gómez de la Serna y Juan Manuel Montalbán, Elementos de Derecho civil y penal de España, precedidos de una reseña histórica de la legislación española, Madrid, 1841, tomo II, p.87

48 Juan Francisco Lasso Gaite, Crónica de la codificación española, IV. Codificación civil, tomo II, Madrid, 1979, pp.321-496.

49 Juan Baró Pazos, La codificación del Derecho civil en España (1808-1889), Santander, 1992, pp.85 y ss, o "La influencia del Código civil francés (1804) en el Código civil español (1889)", La codificación española. Una aproximación doctrinal e historiográfica a sus influencias extranjeras, y a la francesa en particular, Madrid, 2014, pp.75-88.

50 Además del Código de 1804, ya se había traducido al español la obra de Robert Joseph Pothier, Tratado de la location, conduccion, por Pothier, traducido al español con notas de derecho patrio por una sociedad de amigos colaboradores. Barcelona, 1841, que ejercería una gran influencia en la regulación de este contrato.

51 José María Manresa y Navarro, Comentarios al Código Civil español, Madrid, tomo X, 1908, p.725.

52 Francisco García Goyena, Concordancias, motivos y comentarios del Código civil español, tomo 3, Madrid, 1852, pp.480-482, Manuel Falcón, Código civil español, ilustrado con notas, concordancias, motivos y comentarios, vol.5, Madrid, 1890, pp.178-182, o José Maria Manresa y Navarro, Comentarios al Código Civil español, Madrid, tomo X, 1908, pp.725-739 
derivados de las nuevas condiciones de trabajo que surgieron con el liberalismo económico y el desarrollo del sistema capitalista, en el escenario de la sociedad de mercado.

La expresión iba mucho más allá del mero concepto de pauperismo o pobreza tradicional, heredado del Antiguo Régimen y afrontado desde la caridad privada, al que se aferraron los liberales, y señalaba los errores derivados de la "utopía liberal" de la autorregulación de las condiciones de trabajo en un mercado libre. Era una llamada de atención sobre las nefastas consecuencias derivadas de la división entre capital y trabajo, y la necesidad de corregirla ${ }^{53}$.

Es cierto que, en un primer momento, la "utopía liberal" se enfrentó desde otra utopia, el "socialismo utópico" de los seguidores de Cabet, Fourier o SaintSimon en Francia. Los fourieristas, desde el propio Fourier hasta Considerant o Maurize, entre otros ${ }^{54}$, fueron los primeros en señalar los males derivados de la industrialización y el sistema capitalista (la extrema pobreza, el hambre, la falta de viviendas, el hacinamiento en torno a las fábricas, la opresión, la insalubridad, las enfermedades, la explotación infantil, etc.), y exigieron la desmantelación del régimen liberal para construir en su lugar otro régimen de carácter socialista a través de comunidades ideales (los falansterios), en la que los bienes sería socializados y pertenecerian a toda la comunidad 55 . No obstante, el primero que utilizó propiamente la expresión "question sociale" fue un saint-simoniano, Lechevalier, en su obra Question sociale, de la réforme industrielle, considerée comme problème fondamental de la politique positive (París, 1834) ${ }^{56}$.

La expresión "question sociale" triunfaría a partir de ese momento dentro y fuera de Francia ("cuestión social" en España o "soziale Frage" en Alemania; aunque en Inglaterra seguiría hablándose simplemente de pobreza/ "poverty", a pesar de ser pionera en la industrialización); y se utilizaría profusamente para señalar los problemas de las clases trabajadoras. Frente a ella, reaccionaron los liberales más conservadores o "doctrinarios" recuperando con fuerza el discurso de la propiedad privada, la acumulación de la riqueza y el libre juego de las fuerzas económicas como la única fórmula para lograr el progreso y superar los problemas sociales.

Hombres como Tracy ${ }^{57}$, Tocqueville ${ }^{58}$, Horace Say ${ }^{59}$, Sismondi60, Bastiat ${ }^{61}$, Thiers $^{62}$, Chevalier ${ }^{63}$, Dunoyer ${ }^{64}$ o Garnier ${ }^{65}$, negaron así el problema obrero en

53 Ferdinand Tönnies, Desarrollo de la cuestión social, op. cit., pp.26-31.

54 Charles Fourier, Ouvres Complètes, Tome Sixième: La nouveau monde industriel et sociétaire ou invention du procédé d'industrie attrayante et naturelle, Paris, 1829-1830, Victor Considerant, Destinée sociale, Paris, 1834, pp.4-16, o Nécessité d'une derniere débácle politique en France, París, 1836, pp.145-152, o A Maurize, Dangers de la situation actuelle de la France: aux hommes sinceres de tous les partis, Paris, 1832. También pueden consultarse la revista de la escuela fourierista La Réforme Industrielle ou le Phalanstere.

55 Louis Reybaud, Études sur les réformateurs contemporains ou socialistes modernes, SaintSimon, Charles Fourier, Robert Owen, par M. Louis Reybaud, Paris, 1840.

56 Gonzalo Capellán de Miguel, "Cambio conceptual y cambio histórico. Del pauperismo a la "cuestión social”, Historia Contemporánea, 29 (2005), p.548, y Enciclopedia del pauperismo, vol. I, Universidad de Castilla-La Mancha, 2007, pp.21-91.

57 M. le comte Destutt de Tracy, Traité d'economie politique, Paris, 1823.

58 Alexis de Tocqueville, Memoir on pauperism, Paris, 1835, y Alexis de Tocqueville, Contre le droit au travail, préface de Pierre Bessard, Les Belles Lettres, à paraître le 14 septembre 2015. 
pleno siglo XIX, y siguieron defendiendo los postulados básicos de la "economía politica" liberal: la libre concurrencia o competencia como única manera de acabar paulatinamente con los "sufrimientos sociales"; la progresiva civilización que se alcanzaría en la sociedad de mercado como solución a la pobreza, propia de pueblos incivilizados; y la conveniencia de afrontar los "desajustes sociales" que se produjeran hasta entonces simplemente desde la caridad o la beneficencia, sin ninguna intervención pública.

La teoría liberal de estos economistas antiestatistas franceses del siglo XIX, basados en la doctrina de Smith, Turgot o Jean-Baptiste Say, siguió siendo la corriente mayoritaria y oficial que imperó en Francia hasta la Revolución de 1848. Pero poco a poco el discurso liberal comenzó a admitir algunos matices de interés. Así, por ejemplo, aunque en la estadística de pobres publicada por Michel Lux en 1841 se continuaba relacionando fundamentalmente la solución de la pobreza de las clases trabajadoras con la misericordia o piedad cristiana; el autor se permitía también hacer una llamada de atención al poder público, que en su opinión no podía permanecer ajeno al problema social por la amenaza que las clases trabajadoras empezaban a suponer para el mantenimiento del Estado liberal66.

En este mismo sentido se pronunciaría en los años cuarenta Charles de Remusat, Ministro del Interior, para quien el gobierno debía tratar de auxiliar a las clases más desfavorecidas, prestándoles una protección de mínimos a través de una intervención de carácter muy excepcional (lo que denomina un derecho de "caridad legal" o "charité légale")67, al objeto de evitar que el sistema liberal se

Sobre su pensamiento en torno a la cuestión, Eric Keslassy, Le libéralisme de Tocqueville à l'épreuve du paupérisme, Paris, 2000, pp.236-240.

59 Horace Say, Avant-propos à la discussion d'une nouvelle loi sur les faillites, Paris, 1837. Horace Say también reeditó las obras de economía política de su padre, Jean-Baptiste Say, quien fuera uno de los principales introductores de la ideas de Adam Smith en Francia: Petit volume contenant quelques aperçus des hommes et de la société, par Jean-Baptiste Say, troisième édition entièrement refondue par l'auteur et publiée sur les manuscrits qu'il a laissé, par Horace Say, Paris,

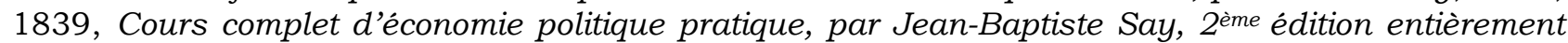
revue par l'auteur, publiée sur les manuscrits qu'il a laissés et augmentée de notes par Horace Say, Paris, 1840, o Traité d'économie politique, par J.-B. Say, бe édition publiée par Horace Say, Paris, 1841.

60 Jean-Charles-Léonard Simonde Sismondi, Études sur l'economie politique, Paris, 1838.

${ }^{61}$ Frédéric Bastiat, "Propriété et loi, justice et fraternité", Journal des économistes, Paris, 1848.

62 Adolphe Thiers, De la propriété, Paris, 1848.

63 Michel Chevalier, Cours d'économie politique du Collège de France. Discours d'ouverture de l'année scolaire 1843-44, par Michel Chevalier (extrait du Journal des économistes), Paris, 1844.

${ }^{64}$ Charles Dunoyer, De la liberté du travail ou simple exposé des conditions dans les quelles les forces humaines s'exercent avec le plus de puissance, París, 1845, 3 vols..

65 Joseph Garnier, Introduction à l'étude de l'économie politique, avec des considérations sur la statistique, la liberté du commerce et l'organisation du travail. Ouverture du cours d'économie politique à l'Athénée, le 4 janvier 1843, Paris, 1843.

${ }^{66}$ Michel Lux, De la question du pauperisme sous le point de vue politique et social ou Memorire a l'occasion de la statistique de pauvres, Paris, 1842. Cfr. Gonzalo Capellán de Miguel, "Cambio conceptual y cambio histórico. Del pauperismo a la "cuestión social", op.cit., p.554.

${ }^{67}$ Charles de Remusat, Du paupérisme et de la Charité Légale, Paris, 1840. 
resquebrajara desde la base y pudiera seguir funcionando en su conjunto. Detectados los errores del viejo liberalismo individualista, el propio pensamiento liberal proponía así corregirse para asegurar su supervivencia, señalando una intervención parcial y mínima frente al abandono absoluto del individuo a las fuerzas del mercado.

A consecuencia de esta forma de pensar, y en atención al estudio que la Academia de Ciencias Morales y Politicas, refundada por el doctrinario Guizot en 1832, había encargado hacer a Louis René Villermé sobre las condiciones de vida de las clases obreras ${ }^{68}$, en 1841 se promulgaba en Francia la primera ley de "caridad legal" sobre el trabajo de los niños: la ley de 22 de marzo de 1841 . La norma prohibía el trabajo a los menores de 10 años y el trabajo nocturno a los menores de 13 años, y limitaba la jornada de trabajo a los niños de hasta 16 años ${ }^{69}$. Pero para muchos autores, estas prevenciones eran claramente insuficientes.

Por ello, frente al liberalismo clásico, y superando las propuestas de comunidades ideales de los primeros "socialismos utópicos", no tardó en surgir en Francia una tercera corriente a través de la idea de la organización del trabajo a través del derecho ("organisation du travail'), que desarrolló fundamentalmente Louis Blanc ${ }^{70}$, e incluso del replanteamiento del sagrado concepto de la propiedad privada, tal y como hiciera Proudhon levantando una enorme polémica ${ }^{71}$.

Entre los seguidores de esta nueva corriente de pensamiento, que se comenzó a denominar "socialista", destacaron personajes como Leroux ${ }^{72}$, Considerant ${ }^{73}$ o Gratiot $^{74}$, que exigian profundas reformas sociales a través de una mayor intervención pública para la protección de las clases trabajadoras. En concreto, proponian una legislación social para proteger a los trabajadores más débiles (mujeres y niños), pero también para asegurar aspectos básicos como la vivienda, la higiene, el salario, el descanso, el derecho de reunión, o el derecho mismo a trabajar ("droit au travail").

Los debates entre las dos formas antagónicas de entender la propiedad y el trabajo, la de los liberales y la de los socialistas, tuvieron su más vívido momento en la Asamblea nacional que se constituyó tras la Revolución de 1848, en la que, como es sabido, tuvieron un enorme protagonismo las clases trabajadoras y su

68 Louis René Villermé, Tableau de L'État physique et moral des ouvriers employés dans le manufactures de coton, de laine et de soie, Paris, 1840.

69 Edouard Dolléans et Gérard Dehove, Histoire du travail en France, mouvement ouvrier et législation sociale, vol. 1: Des origines à 1919, Paris, 1953.

70 Jean Joseph Charles Louis Blanc, Organisation du travail, Paris, 1839.

71 Pierre Joseph Proudhon, Qu'est-ce que la propriété?, París, 1840. Y entre quienes le contestaron, por ejemplo, Cherbuliez, Lettre à M. Proudhon sur le droit de propriété, extrait du Journal des économistes, Paris, 1848

72 Los escritos de Pierre Leroux se publicaron fundamentalmente en los periódicos Le Globe (1824), Encyclopédie nouvelle (1836-1843) y la Revue indépendente (1841-1848). Sobre su pensamiento, Vicent Peillon, Pierre Leroux et le socialisme républicaine: une tradition philosophique, Bord de 1'Eau, 2003.

73 Victor Prosper Considérant, Le socialisme devant le vieux monde, Paris, 1848.

74 Amédée Gratiot, Organisez le travail, ne le désorganisez pas. Lettre aux ouvriers, Paris, 1848, y Messiers les socialistes, une solution, s'il vous plaît, Paris, 1848. 
demanda del derecho a trabajar ("droit au travail') ${ }^{75}$. La insurrección popular que, alentada por la crisis económica, se produjo en febrero de 1848 contra el gobierno doctrinario de Guizot, obligó finalmente a abdicar a Luis Felipe I de Francia y precipitó la Constitución de la Segunda República francesa, formándose un gobierno provisional que convocó la Asamblea nacional que debía aprobar la nueva Constitución de 1848.

Haciéndose adalid de las demandas que habian alentado la insurrección, basadas fundamentalmente en la defensa de un derecho a trabajar frente a los problemas económicos y sociales derivados de la crisis (la defensa retardada, decían, del famoso valor de la fraternidad o "fraternité" de la originaria trilogía revolucionaria "liberté, égalité, fraternité", que se reconoció en el artículo IV del preámbulo), en el nuevo proyecto de Constitución que se presentó a la Asamblea nacional, el gobierno provisional introdujo la protección del trabajo como un derecho básico tanto en el artículo VIII del preámbulo, como en el artículo 13, que exigía la intervención de la República para desarrollar el trabajo a través de la enseñanza, la educación profesional, la igualdad con los empleadores, el derecho de asociación para los trabajadores, el trabajo público y la asistencia social.

Los debates parlamentarios en torno a estos artículos produjeron, según Fernand Tanghe, una importante evolución del derecho al trabajo ("droit au travail'), que sufrió un enriquecimiento de su contenido y adquirió connotaciones más profundas que el mero derecho a trabajar ("droit de travallier') ${ }^{76}$. Sobre el mismo, se enfrentaron dos posiciones irreconciliables. Para los liberales el derecho al trabajo destruiría la libertad de trabajo, convertiría al Estado en una especie de fabricante o mercader con responsabilidades privadas, y le cargaría con enormes deudas que no podria asumir con la hacienda pública. Para los socialistas, por el contrario, el derecho al trabajo era la condición de realización de la libertad de trabajo, el presupuesto de la fraternidad o solidaridad entre todos los franceses, el principal instrumento para salir de la crisis y fortalecer el Estado, y, en definitiva, la garantía del derecho a la vida de todos los ciudadanos $^{77}$.

Un ejemplo de la primera posición, lo tenemos en Faucher, futuro Ministro de Interior de Luis Bonaparte: "Il ne faut pas confondre le droit au travail, cette prétention des socialistes, avec le droit de travallier, cette propriété de tout homme, dont Turgot a dit, avec raison, qu'ell était la premiére, la plus sacrée et la plus imprescriptible de toutes. Le droit de travailler nèst pas autre chose que la liberté qui

75 Gérard Lyon-Caen, "La liberté du travail et le droit français du travail", La liberté du travail, congrès et colloques de l'université de Liège, vol. 53, université de Liège, 1969, pp.21-28, Francis Demier, "Les ouvriers de Rouen parlent à un économiste en juillet 1848", Le Mouvement social, $\mathrm{n}^{\circ} 1$ 19, 1982, avril-juin, pp.3-32, William H. Sewell, Trabajo y revolución en Francia: el lenguaje del movimiento obrero desde el antiguo régimen hasta 1848, Madrid, 1992, o Jacques Le Goff, Du silence à la parole, Une histoire du droit du travail des années 1830 à nos jours, Rennes, 2004, pp.84-92.

76 Fernand Tanghe, Le droit au travail entre histoire et utopie. 1789-1848-1989: de la répression de la mendicité à l'allocation universelle, Bruxelles, 1989, pp.42 y 45.

77 Fernand Tanghe, Le droit au travail entre histoire et utopie. 1789-1848-1989: de la répression de la mendicité à l'allocation universelle, Bruxelles, 1989, Thomas Bouchet, Un jeudi à l'Assemblée. Politiques du discours et droit au travail dans la France de 1848, Quebec, 2007, o Samuel Hayat, "Les controverses autour du travail en 1848", Raisons politiques, n47, août 2012, pp.13-34. 
appartient à chaque individu de faire de son intelligence, de sus bras et de son temps, l'emploi qu'il juge le plus profitable.tandis que le droit au travail est une action que l'on donne à l'individu contre la société"78.

El mismo Faucher, afirmaría también ante la Asamblea que "par le droit au travail on crée en même temps un droit et une obligation. On suppose un contrat entre l'individu et la société, aux termes duquel la société devrait l'existence à chacun de ses membres, contrat non synallagmatique et qui n'engagerait qu'une des parties. Car tandis que l'Etat devrait fournir aux individus, sur leur demande, les moyens de travallier, il ne serait pas armé du pouvoir de les contraindre à chercher dans le travail leur subsistance habituelle (...) Le droit au travail est une servitude que lón impose à la communauté tout entière, dans l'intérêt de quelques-uns"79.

Frente a los liberales, que seguian relacionando el trabajo con la idea de libertad y propiedad del liberalismo clásico ("laissez faire, laissez passer"), los socialistas viraron el concepto del derecho al trabajo hacía el ámbito de influencia del derecho a la vida, como garantía para la existencia de los individuos ("pour des millions de créatures humaines, le laissez-passer, c'est le laisser-mourir", diria Blanc $\left.{ }^{80}\right)$ : "Este-il vrai, oui ou non, que tous les hommes apportent en naissant un droit à la vie? Est-il vrai, oui ou non, que le pouvoir de travailler est le moyen de réalisation du droit de vivre? Est-il vrai, oui ou non, que si quelques-uns parviennent à se faire esclaves des premiers, ou à mourir? Est-il juste que tous ayant apporté, en naissant, le droit à la vie, le pouvoir de réaliser ce droit soit concentré aux mains de quelques-uns, de telle sorte que l'espèce humanine se trouve divisée en deux classes d'hommes dont les uns vendent la vie, que les autres sont réduits à acheter?"81.

Desde esta perspectiva, la libertad de trabajo y el derecho a trabajar ("droit de travallier') que defendian los liberales, no era para los socialistas sino un reducto de los privilegios de las clases poderosas, un resurgimiento feudal por el cual sólo unos pocos podían asegurarse la supervivencia y la propiedad. En palabras de Billaut: "Qu'est-ce qu'en effet que la liberté du travail? C'est selon vous le droit de travallier quand on a du travail; mais quand on n'a plus de travail, on n'a plus le droit de travallier, on n'a plus la liberté du travail. Qu'est-ce que donc qu'une liberté, qu'un droit qui n'est pas à tous, qui ne dépend pas de nous, qu'on a ou qu'on n'a pas au gré d'autrui? Mais c'est un privilège" 82 .

78 Cfr. Fernand Tanghe, Le droit au travail entre histoire et utopie, op. cit., p.45, citando a su vez el original de Joseph Garnier (ed.), Le droit au travail à l'Assemblée Nationale. Recueil complet de tous les discours prononcés dans cette memorable discussion, Paris, 1848, p.344.

79 Cfr. Fernand Tanghe, Le droit au travail entre histoire et utopie. op. cit., p.45, citando a su vez el original de Joseph Garnier (ed.), Le droit au travail à l'Assemblée Nationale. Recueil complet de tous les discours prononcés dans cette memorable discussion, Paris, 1848, pp.344-345. Para conocer más sobre el pensamiento de Leon Faucher sobre el derecho al trabajo, véase Leon Faucher, "Opinion sur le droit au travail", Journal des économistes, 21 (oct., 1848), pp.345-368.

80 Fernand Tanghe, Le droit au travail entre histoire et utopie, op. cit., p.86.

81 Cita de Blanc, cfr. Fernand Tanghe, Le droit au travail entre histoire et utopie, op. cit., p.61.

82 Joseph Garnier (ed.), Le droit au travail à l'Assemblée Nationale, op. cit., p.254. 
El apoyo de los republicanos a los socialistas en esta cuestión, permitió que finalmente el articulado de la Constitución de 1848 quedara aprobado en los términos propuestos en el proyecto, con escasas diferencias. El artículo IV del preámbulo realzaba el valor de la fraternidad o la solidaridad: "Elle -la République- a pour principe la Liberté, l'Egalité et la Fraternité. Elle a pour base la Famille, le Travail, la Propriété, l'Ordre public". El artículo VIII del preámbulo, por su parte, establecía que: "La République doit protéger le citoyen dans sa personne, sa famille, sa religion, sa propriété, son travail, et mettre à la portée de chacun l'instruction indispensable à tous les hommes; elle doit, par une assistance fraternelle, assurer l'existence des citoyens nécessiteux, soit en leur procurant du travail dans les limites de ses ressources, soit en donnant, à défaut de la famille, des secours à ceux qui sont hors d'état de travailler".

Y finalmente, el artículo 13 rezaba: "La Constitution garantit aux citoyens la liberté du travail et de l'industrie. La société favorise et encourage le développement du travail par l'enseignement primaire gratuit, l'éducation professionnelle, l'égalité de rapports, entre le patron et l'ouvrier, les institutions de prévoyance et de crédit, les institutions agricoles, les associations volontaires, et l'établissement, par l'Etat, les départements et les communes, de travaux publics propres à employer les bras inoccupés ; elle fournit l'assistance aux enfants abandonnés, aux infirmes et aux vieillards sans ressources, et que leurs familles ne peuvent secourir".

En desarrollo de estos artículos constitucionales, la Segunda República consiguió impulsar la ley que limitaba a diez horas la jornada laboral, o el establecimiento de talleres nacionales para crear empleo en el país. Pero estos avances fueron efimeros. El triunfo electoral de Luis Napoleón Bonaparte el 10 de diciembre de 1848, y su posterior golpe de Estado el 2 de diciembre de 1851 para reforzar su poder y modificar la Constitución de 1848, pusieron fin a este primigenio desarrollo del derecho al trabajo en Francia.

La Constitución del Segundo Imperio aprobada en 1851 no hacía mención alguna al derecho al trabajo, como tampoco la hacía a ningún otro derecho individual. Era una Constitución orgánica. No obstante, la necesidad de apoyos que más adelante necesitó Luis Napoleón Bonaparte, Napoleón III, para el mantenimiento de su régimen, determinó que pudieran impulsarse algunas leyes de interés en favor de la clase trabajadora, como la ley de 25 de mayo de 1864, que permitía el derecho de asociación y huelga, o las ley de 9 de abril de 1898 sobre accidentes de trabajo.

Tras la caída de Napoleón III en 1870, a causa de su derrota en la guerra franco-prusiana, y tras los acontecimientos vividos durante el breve gobierno popular de la Comuna de París en 1871, las Leyes Constitucionales de la Tercera República francesa, que tampoco trataban expresamente del derecho al trabajo, favorecieron en la misma línea la constitución de partidos políticos de base obrera y permitieron el desarrollo del sindicalismo. El auge del derecho obrero se hizo a partir de este momento imparable ${ }^{83}$.

83 Jean-Pierre Le Crom (éd.), Deux siècles de droit du travail: l'histoire par les lois, Paris, 1998, o Alain Cottereau, "Droit et bon droit. Un droit des ouvriers instauré, puis évincé par le droit du travail (France, XIXe siècle)", Annales HSS, n² 2, nov.-déc. 2006, pp. 1521- 1557. 


\section{V.- PROPIEDAD Y "REFORMA SOCIAL" EN LA ESPAÑA DE FINALES DE SIGLO XIX.}

En la España isabelina, moderada y rural, la revolución francesa de 1848 apenas tuvo influencia. Se conocieron, eso sí, sus ideas "socialistas", y comenzó a hablarse también de la "cuestión social", término que incorporó ya por primera vez a finales de la década de los treinta Álvaro Flórez Estrada, y que le sirvió para plantear su proyecto de desamortización en conflicto con el derecho de propiedad privada ${ }^{84}$.

Los planteamientos de Flórez Estrada, en lo referente en particular a la corrección del sagrado derecho de propiedad, hicieron reaccionar a la mayoría de la clase moderada, seguidora del liberalismo individualista clásico de Smith, Turgot, Say o Bastiat (algunos de los autores más traducidos en nuestro país), y representada en este momento por hombres como José Canga Argüelles, Federico Mendizábal, Antonio Alcalá Galiano o Juan Donoso Cortés, quienes reforzaron la defensa del derecho de propiedad y la libertad del individuo, en los términos reconocidos en la Constitución de 1845, como únicos instrumentos para asegurar el progreso de la nación.

También se pronunció en este temprano debate Ramón de la Sagra, buen conocedor de las ideas socialistas francesas y responsable de introducir en España el concepto "organización del trabajo" ("organisation du travail'), acuñado en Francia por el mismo Louis Blanc ${ }^{85}$. La obra de Ramón de la Sagra se publicaba el año de 1848 en Francia y en francés ${ }^{86}$. Denunciaba la desequilibrada distribución de la riqueza en la sociedad, exigía una organización más justa del trabajo, e incluso planteaba la asociación de los bienes y el trabajo como solución a los problemas sociales. Pero, a diferencia de lo que hicieran los socialistas franceses, no se atrevia a cuestionar el derecho de propiedad.

En esta misma línea, que de forma temprana apostaba por la "organización del trabajo" sin rechazar la propiedad privada, y que planteó originariamente en España una cierta intervención del Estado más allá de la caridad (un paliativo, decían, pero no la solución del problema), deben citarse también a Fernando Garrido, Federico Beltrán del Rey o Sixto Cámara ${ }^{87}$. Sus ideas no tuvieron un amplio calado en la sociedad de la época, y se perdieron entre otras propuestas más conservadoras dadas desde el individualismo liberal clásico por personajes como Donoso Cortés a lo que él llamaba el "problema social"88. Pero, al menos, sirven para demostrar que las ideas "socialistas" francesas y la expresión "cuestión social" eran ya ampliamente conocidas en la España moderada de mediados de siglo.

84 Gonzalo Capellán de Miguel, "Álvaro Flórez Estrada y la "cuestión social", Álvaro Flórez Estrada (1766-1853), politica, economia, sociedad, Oviedo, 2003, pp.475-507, o Gonzalo Capellán de Miguel, "Cambio conceptual y cambio histórico. Del pauperismo a la "cuestión social", op.cit., pp. 561-565.

85 Gonzalo Capellán de Miguel, "Cambio conceptual y cambio histórico. Del pauperismo a la “cuestión social", op.cit., pp.564-567.

86 Ramón de la Sagra, Organisation du travail: questions preliminaries à l'examen de ce probleme, Paris, 1848.

87 Adan Elorza, Socialismo utópico español, Madrid, 1970, pp.160-194.

88 Donoso Cortés, Lecciones de derecho politico, Madrid, 1836. 
La expresión "charité légale", que comenzara a utilizarse en Francia en la década de los cuarenta para defender una cierta intervención estatal contra la pobreza, era asimismo utilizada ya en 1843 por José Posada Herrera en sus Lecciones de Administración. Posada Herrera distinguía la "caridad legal" de la caridad privada y de la beneficencia como acción administrativa del Estado ${ }^{89}$, concluyendo que "el legislador solo puede confiar en la caridad privada para el alivio de los pobres"90 e impulsar en la medida de lo posible la beneficencia. Es decir, si utilizaba la expresión "caridad legal", "monstruo que amenazaba devorar las sociedades modernas" citando a los discipulos de Malthus, era para rechazar la idea desde la postura individualista, no para apoyarla; aunque, al menos, su crítica nos sirva para concluir que la polémica era conocida en nuestro país casi de forma coetánea al país vecino ${ }^{91}$.

El momento de mayor relevancia en el debate sobre la "cuestión social" y el intervencionismo estatal no se produciria en España, sin embargo, hasta la apertura intelectual que permitió la Revolución Gloriosa de 1868, que puso fin al gobierno moderado de Isabel II, y la posterior etapa "armonicista" que supuso la Restauración borbónica en la figura de Alfonso XII, a partir de $1876^{92}$. En este periodo de tiempo, no sólo pudieron aflorar y desarrollarse en el país las posturas socialistas que hasta entonces habian estado condenadas a la clandestinidad, gracias al reconocimiento del derecho de asociación en las Constituciones de 1869 y 1876, sino que también eclosionó en el debate político el pensamiento reformista del liberalismo progresista, de origen krausista.

Dejando a un lado el todavía muy incipiente ideario socialista de base obrera, en este particular momento histórico que supusieron las últimas décadas del siglo XIX, cabe destacar especialmente el movimiento de "reforma social" que impulsó el pensamiento liberal progresista frente a los postulados del liberalismo moderado o conservador. La "reforma social" de los progresistas tomaba en esencia el testigo de la traducción moderada que hizo Ramón de la Sagra sobre la "organización del trabajo" francesa (compatibilizándola con la propiedad privada), y desarrollaba esta idea a partir de la filosofia krausista que clamaba por la

89 José de Posada Herrera, Lecciones de administración, tomo IV, Madrid, 1845, p.19: "La sociedad puede creerse en el deber de mantener á todas las personas que no posean ningunos, ó no posean los bastantes medios de subsistencia; puede creerse solo obligada á mantener los individuos que no teniendo de qué vivir, no tengan tampoco aptitud para el trabajo por incapacidad fisica o moral; puede pensar que si los sentimientos de humanidad y su propio interés la estimulan á aliviar los males de la pobreza, no le imponen obligación alguna exigible, y que por consiguiente no está en el deber de emplear medios que graven de una manera exorbitante á las clases acomodadas, y puede en fin mirar como propio de los particulares el ejercicio de la caridad y beneficencia, creyendo que solo compete al poder público influir de una manera indirecta y por disposiciones legislativas en la riqueza respectiva de las clases de la sociedad, sin cuidarse especialmente de los individuos. Al primero y segundo de estos sistemas se le ha dado el nombre de caridad legal; al tercero beneficencia pública".

90 José de Posada Herrera, Lecciones de administración, op.cit., p.23.

91 Tras plantear la cuestión, José de Posada Herrera, Lecciones de administración, op.cit., p.24, concluye: "La acción administrativa dirige y auxilia la caridad privada, pero sin imponerla coacción alguna ni impedir su libre exercicio".

92 Ángel Marvaud, La cuestión social en España, Madrid, 1975. 
aplicación de la ética al derecho, buscando el entendimiento armónico del hombre y la sociedad ${ }^{93}$.

El pensamiento krausista, que debe su nombre al filósofo alemán Krause, fue introducido en España por Julián Sanz del Río, catedrático de Historia de la Filosofia de la Universidad Central, y sirvió de revulsivo para la intelectualidad progresista, pudiendo contarse entre sus fijas a personajes cómo Giner de los Ríos, Nicolás Salmerón, Francisco de Paula Canalejas, Emilio Castelar, Gumersindo de Azcárate o Segismundo Moret. El movimiento adquirió fuerza con la creación, en 1876, de la Institución Libre de Enseñanza, dirigida primero por Giner de los Ríos y más adelante por Manuel Bartolomé Cossio; y contó con importantes focos de difusión, como el formado por el llamado "grupo de Oviedo", de gran proyección nacional e internacional, y formado por hombres como Adolfo Posada, Adolfo Álvarez Buylla, Aniceto Sela, Rafael Altamira o Leopoldo Alas ${ }^{94}$.

Con su propuesta ética y armónica, los krausistas jugaron un papel trascendental en la redefinición de la "cuestión social" y de la "cuestión obrera", hasta entonces enquistada en una frontal lucha de clases. Para ellos, la cuestión obrera sólo era parte de una más amplia cuestión social que había que resolver necesariamente para que el Estado liberal pudiera funcionar sin fricciones. Su solución pasaba por la llamada "reforma social", es decir, una intervención mínima que se exigía desde la humanidad o la filantropía para proteger la salud moral y material de los trabajadores, y para evitar las consecuencias más negativas (hambre, enfermedades, trabajo de mujeres y niños, etc.) que se habian derivado del principio de la "libertad de trabajo".

Como dijera Castelar, lo que la corriente de la "reforma social" proponía para resolver la cuestión obrera no era un "derecho al trabajo", como los franceses, sino un "derecho a la asistencia"95; es decir, una ordenación mínima del trabajo. Si la humanidad y la ética eran los presupuestos (el "dolor" de los desfavorecidos o los desheredados de la tierra), el derecho comenzó a exigirse como parte esencial de la solución. Gumersindo de Azcárate lo explicaba argumentando que la consecuencia de la revolución burguesa habia sido "el predominio de la libertad $y$ del derecho, como en el antiguo régimen predominaron la autoridad y el deber; antes se le decía al hombre lo que está obligado á hacer; luego se le dijo lo que está facultado para hacer (...), si antes predominaba el status, la condición juridica $y$

93 Feliciano Montero García, "La polémica sobre el intervencionismo y la primera legislación obrera en España (1890-1900). Primera parte: el debate académico", Revista del Trabajo, nums.59-60 (1980/1981) pp.121-165, Bartolomé Clavero, "Institución de la reforma social y constitución del Derecho del Trabajo", Anuario de Historia del Derecho Español, 49 (1989), pp. 859-884, Manuel Carlos Palomeque López, Derecho del Trabajo e ideología. Medio siglo de formación ideológica del Derecho Español del Trabajo (1873-1923), Madrid, 5ª edic., 1995, José Luis Monereo Pérez, Fundamentos doctrinales del derecho social en España, Madrid, 1996, o Miguel Ángel Cabrera, El reformismo social en España (1870-1900), Madrid, 2014.

94 Elías Díaz García, La filosofía social de Krausismo español, Madrid, 1973, Juan José Gil Cremades, Krausistas y liberales, Madrid, 1981, o Gonzalo Capellán de Miguel, La España armónica: el proyecto del krausismo español para una sociedad en conflicto, Madrid, 2006.

95 Emilio Castelar, Discursos académicos, Madrid, 1881, p.171. Véase también, Emilio Castelar, La fórmula del progreso, Madrid, 1870 o Estudios sobre el socialismo, Madrid, 1890. 
social impuesta de arriba, ahora predomina el contrato, determinándose así aquélla mediante la libre actividad de cada uno. (...)"96.

Frente ello, continuaba Azcárate, para superar el enfrentamiento entre los liberales "individualistas" y los "socialistas", había que acometer "reformas positivas" capaces de llevar "al derecho civil el espiritu de progreso que informa todas las esferas del derecho público; en una palabra, la aspiración á que la sociedad moderna cristalice de nuevo, aunque sobre distinta base que la antigua, para que pierda la disgregación que hoy la caracteriza, y salga del atomismo reinante por virtud de una reorganización. El tránsito del segundo al tercer periodo determina la crisis en que estamos empeñados y el problema social, que á todo el mundo preocupa"97.

En este mismo sentido, cabe destacar también, por citar otro ejemplo de gran trascendencia en la época, la contribución de Adolfo Posada en su estudio preliminar a la obra de Antonio Menger, "El derecho civil y los pobres", en la que afirmaba que "uno de los más claros defectos de las doctrinas sociales modernas, tal cual aparecen formuladas en los economistas y en los socialistas anarquistas, es el que resulta de que las formulan gentes, que apenas si se han dado cuenta de que el Derecho es algo real y vivo, $y$ algo con que inevitablemente se ha de tropezar, cada vez que se quiera transformar, para mejorarla, la condición de los hombres $(\ldots)^{\prime \prime 98}$.

Si hasta este momento la solución de la cuestión social sólo se había afrontado desde la economía o moral, la aportación de los reformistas sociales españoles fue defender que la cuestión social era, ante todo, un "problema de la ciencia del Estado y del Derecho"99, y por tanto requería una cierta intervención jurídica para corregir los desequilibrios entre las distintas clases sociales que había propiciado la total ausencia de protección pública, aunque sin conculcar en ningún caso los principios de propiedad y libertad reconocidos en los primeros textos constitucionales. De hecho, el derecho de propiedad privada fue especialmente protegido por la doctrina jurídica en este momento histórico, con obras como la del propio Azcárate sobre la historia del derecho de propiedad ${ }^{100}$.

Las posturas conservadoras no tardaron en reaccionar contra estos postulados $^{101}$, advirtiendo de los peligros del socialismo ${ }^{102}$, e indicando que

96 Gumersindo de Azcárate, Alcance y significación de las llamadas leyes obreras, Discurso leído en el Ateneo Científico y Literario de Madrid, Madrid, 1893, pp.15-16. Véase también Gumersindo de Azcárate, Estudios económicos y sociales, Madrid, 1876, o Resumen de un debate sobre el problema social, Madrid, 1881. 16.

97 Gumersindo de Azcárate, Alcance y significación de las llamadas leyes obreras, op.cit., pp.15-

98 Adolfo Posada, "El derecho y la cuestión social. Estudio preliminar", El derecho civil y los pobres de A. Menger, Madrid, 1898, p.8. Sobre el pensamiento de Adolfo Posada, véase José Luis Monereo Pérez, La reforma social en España: Adolfo Posada. Madrid, 2003.

99 Adolfo Posada, "El derecho y la cuestión social. Estudio preliminar", op.cit., p.9.

100 Gumersindo de Azcárate, Ensayo sobre la historia del derecho de propiedad y su estado actual en Europa (1879-1883), 3 tomos, Madrid, 1840-1917.

101 Antoni Jutglar, "Actitudes conservadoras ante la realidad obrera en la etapa de la Restauración", Revista de Trabajo, n²5, Madrid, 1969, pp.47-71. 
cualquier legislación obrera o protección minima que se acometiera desde el Estado no sólo alentaría el creciente movimiento obrero, sino que violaría el derecho de libertad de contratación y de trabajo reconocido por la Constitución: "Se olvida en esta cuestión que entre el obrero y el gefe de industria existe un verdadero contrato, por el cual mediante una cantidad que se llama salario, el obrero aplica su inteligencia y su fuerza al producto que elabora, y asi como el industrial puede separarse de este contrato cesando en su industria ó imponiendo ciertas condiciones, el obrero tiene la misma libertad para dar mayor ó menor valor a su trabajo, y hasta aqui nadie hace sino usar de su derecho; pero desde el momento en que estas condiciones no se proponen sino que se exigen $y$ esta exigencia se hace estensiva á los demás obreros ó á los demas gefes de industria, existe una verdadera violación del derecho"103.

Para los liberales moderados de finales del siglo XIX, sólo el individuo era responsable de mejorar su situación laboral en el escenario de la libertad de trabajo, con sus propios medios y su esfuerzo; y el único recurso que, en última instancia, se debía arbitrar para paliar los efectos más indeseables de la "cuestión social" seguía siendo la beneficencia o la caridad privada, con la religión católica como base: "La condición del trabajador se irá mejorando merced á sus propios esfuerzos y á los resorte que la sociedad encierra en su seno, sin depender de la ayuda directa del Estado"104.

Sin ánimo de ser exhaustiva, entre las voces moderadas que se pronunciaron en estos términos, pueden citarse las de López Serrano ${ }^{105}$, Armengol y Cornet ${ }^{106}$, Pérez Pujol ${ }^{107}$, Santamaría de Paredes ${ }^{108}$ o Millet ${ }^{109}$. Al reflexionar sobre "el derecho de propiedad y sus relaciones con el trabajo", Santamaría de Paredes no dudó en oponerse frontalmente a los socialistas, considerando que la verdadera filosofia era la liberal porque "no pretende alterar la naturaleza, creyéndola imperfecta, aspira tan solo á que se cumplan sus leyes; por eso esclama laissez faire, laissez passer"; y citando a Bastiat afirmaba que desde el orden natural "la propiedad individual es legitima "110. Aunque en el pasado se habian elaborado doctrinas que intentaban justificar la propiedad en el acto individual de la adquisición (teoría de la ocupación y teoría del trabajo), en su opinión "la ocupación y el trabajo no pueden concebirse como fundamento, sino

102 Por citar un ejemplo, Juan López Serrano, La revolución y la propiedad: estudio politico-legal, Madrid, 1872, p.36: "Después de la Revolución de febrero, el partido socialista es el más ardiente y el más temible, y los adeptos á la escuela enciclopedista y los admiradores de Proudhon no cejan ni desisten de elevar su soberbia ó su fortuna sobre las ruinas de España".

103 Pedro Armengol y Cornet, Algunas verdades a la clase obrera, Barcelona, 1874, p.34.

104 Domingo Enrique Aller, El Estado y las clases obreras, Madrid, 1894, pp.193-194.

105 Juan López Serrano, La revolución y la propiedad : estudio político-legal, Madrid, 1872

106 Pedro Armengol y Cornet, Algunas verdades a la clase obrera, Barcelona, 1874.

107 Eduardo Pérez Pujol, La cuestión social en Valencia, Valencia, 1872.

108 Vicente Santamaría de Paredes, La defensa del derecho de propiedad y sus relaciones con el trabajo, Madrid, 1874, La cuestión social en España, Madrid, 1891, o El movimiento obrero contemporáneo, Madrid, 1893.

109 José M. Millet, La cuestión social, $2^{\circ}$ edición, Madrid, 1872.

110 Vicente Santamaría de Paredes, La defensa del derecho de propiedad y sus relaciones con el trabajo, Madrid, 1874, pp.4 y 6. 
como medio de adquirir la propiedad"111; eran el pacto social o la ley los que justificaban la propiedad.

Defendido el origen racional del derecho a la propiedad y su importancia en la producción de la riqueza en la sección primera, Santamaría de Paredes dedicaba la sección segunda de su obra a establecer las relaciones entre el capital y el trabajo, tratando de demostrar que existe una "armonía" entre ambos elementos que el Estado no debía en ningún caso conculcar con leyes civiles; habia que respetar las leyes económicas. Sólo se admitía una excepción en cuanto a las "coaliciones de obreros y las sociedades de resistencia" como "medios de contrarestar la superioridad del capitalista sobre un obrero aislado, fundándose en la libre facultad de contratar y en el derecho de asociación", ya que "estas coaliciones producen el efecto de mantener en vigor la ley de la oferta y del pedido, sin poder sobreponerse á ella"112.

La armonía entre capital y trabajo se convirtió en un tópico en el argumentario moderado: "el capital y el trabajo son profundamente armónicos $y$ solidarios en sus relaciones é intereses, $y$ sus respectivas retribuciones son las naturales y legítimas", diría Millet ${ }^{113}$. Con ello se negaba la necesidad de una intervención pública en materia de salarios, jornada laboral o protección de mujeres y niños (los principales temas para los que se pedía una legislación específica desde los sectores socialistas y progresistas), porque el propio capitalista o empleador establecería de forma armónica y natural los límites requeridos por sus trabajadores, entendiéndose que racionalmente nadie pagaría un salario inferior al necesario para vivir o mantenerse físicamente útil de cara al trabajo, ni exigiría más horas de trabajo de las que fueran rentables para la producción, ni dañaría a sus propios trabajadores siendo mujeres o niños. E1 empleador, argüian los moderados, ajustaría las condiciones teniendo en cuenta que los trabajadores eran un elemento fundamental para la producción.

Otro lugar común para el pensamiento moderado sería la formación de asociaciones, a ser posible mixtas entre patronos y obreros, como la mejor forma de desestabilizar el movimiento obrero. Y, finalmente, el recurso al ahorro y el auxilio mutuo entre los trabajadores, y en última instancia a la beneficencia y la caridad privada (en los términos utilizados por Posada Herrera), como únicos remedios frente a la pobreza.

Aunque estas posiciones moderadas fueron las que todavía imperaron cuando se promulgó la Constitución de 1876 y el posterior Código Civil de 1889, que como se ha visto antes tenía un carácter manifiestamente individualista y dejaba la regulación del trabajo a la autonomía de la voluntad de las partes a través del contrato de arrendamiento de obras o servicios; al publicarse el Código Civil ya se advertía de la importancia que estaban adquiriendo las nuevas corrientes "reformistas" o intervencionistas: "No ha visto el Código en esta materia más especialidades que las que consigna; pero el moderno movimiento social, los nuevos estudios de derecho, encuentran en el contrato de trabajo, especialmente

111 Vicente Santamaria de Paredes, La defensa del derecho de propiedad y sus relaciones con el trabajo, Madrid, 1874, p.46

112 Vicente Santamaría de Paredes, La defensa del derecho de propiedad y sus relaciones con el trabajo, Madrid, 1874, p.242.

113 José M. Millet, La cuestión social op.cit., p.185. 
cuando se trata del trabajo manual, cuando las partes que lo celebran se llaman patrón y obrero, motivos sustanciales que imponen la derogación del derecho clásico, del derecho tradicional. Arranca este nuevo criterio, de un lado, de la observación de los rigores de la lucha económica; de otro, de la elaboración de un nuevo concepto de derecho"114.

Ciertamente, la intervención del Estado frente a la "cuestión social", no sólo cobraba fuerza por la acción de socialistas ${ }^{115}$ y krausistas o progresistas, sino que también comenzó a ser defendida por el catolicismo social desde la publicación de la Encíclica Rerum Novarum de 1891116, o desde posiciones humanitarias eclécticas como las de Concepción Arenal117, Fernando Araujo ${ }^{118}$, o Pedro Dorado Montero ${ }^{119}$. Incluso desde el liberalismo conservador, personajes de la talla de Antonio Cánovas del Castillo ${ }^{120}$ o Eduardo Dato ${ }^{121}$ anunciaron su viraje hacia una concepción más social o "proteccionista" de la economía, y elevaron lo social a una cuestión de Estado, apostando por una mínima protección legal de las clases trabajadoras tras haber comprobado que los postulados tradicionales del librecambismo y la beneficencia o la caridad no habian funcionado. Les apremiaba, además, el miedo a una posible "revolución" del proletariado. De acuerdo con este pensamiento moderado, podemos destacar asimismo a Raimundo Fernández Villaverde ${ }^{122}$.

El fortalecimiento de esta línea doctrinal ${ }^{123}$, sumado a la llegada al poder de destacados pensadores krausistas como Segismundo Moret, Ministro de

114 José $\mathrm{M}^{\mathrm{a}}$ Mansesa y Navarro, Comentarios al Código Civil español, tomo X, Madrid, 1908, pp.727-728.

115 La "cuestión social" en el programa socialista, antes de la influencia marxista que se impondría a lo largo del siglo XX, puede leerse en la obra de Apolinar de Rato, La cuestión social en España, Madrid, 1893.

116 Desde esta perspectiva, pueden citarse en nuestro país a Francisco Pareja de Alarcón, Solución del problema obrero en paz y concordia, Madrid, 1891, Enrique María Repullés y Vargas, El obrero en la sociedad, Madrid, 1892, Amando Castroviejo, El problema Social y su evolución, Granada, 1893, o Maximiliano Arboleya Martínez, Liberales, socialistas y católicos ante la cuestión social, Valladolid, 1901.

117 Concepción Arenal, La cuestión social, Madrid, 1895.

118 Fernando Araujo, "El problema social y el individualismo", La España moderna, 1898.

119 Pedro Dorado Montero, Del problema obrero, Salamanca, 1902.

120 Antonio Cánovas del Castillo "La economía politica y la democracia economista en España" o "De cómo he venido yo a ser proteccionista", Obras. Problemas contemporáneos, III, Madrid, 1890, pp.257-293 y pp.407-449. Véase J M ${ }^{a}$ Serrano Sanz, "Las ideas económicas de Don Antonio Cánovas del Castillo", Antonio Cánovas del Castillo. Homenaje y Memoria de la Real Academia de Ciencias Morales y Politicas (1879-1997), Madrid, 1997, pp.299-316.

121 Eduardo Dato, "Armonía entre el capital y el trabajo. Conferencia pronunciada en la Sociedad El Sitio de Bilbao el 26 de marzo de 1904, La Tribuna El Sitio. 125 años de expresión libre en Bilbao (1875-2000), Bilbao, 2001, pp.781-783, y también Eduardo Dato, La justicia social, Madrid, 1910.

122 Raimundo Fernández Villaverde, "La cuestión social y el derecho civil", Revista General de Legislación y Jurisprudencia, vol.48, n97 (1900), pp.365-388.

123 Alfredo Montoya Melgar, Ideología y lenguaje de las primeras leyes laborales de España, Madrid, 1975, Luis Sánchez Agesta, "Orígenes de la política social en la España de la restauración", Revista de Derecho Politico, Madrid, 1981, n. 8, p. 2-20, Feliciano Montero García, "La polémica sobre el intervencionismo y la primera legislación obrera en España (1890-1900). 
Gobernación que fundó la Comisión de Reformas Sociales en 1883, o Gumersindo de Azcárate, que creó el Instituto de Reformas Sociales en 1903124, impulsaría definitivamente en España el proceso de intervencionismo estatal en las relaciones de trabajo, promoviéndose, con carácter excepcional, una primera legislación obrera proteccionista de las clases trabajadoras. Exponentes de esta nueva legislación obrera, tras el frustrado intento de la Ley Benot de 1873, fueron la ley de accidentes de trabajo de 30 de enero de 1900, la ley de 13 de marzo de 1900 sobre el trabajo de mujeres y niños, y la ley de descanso dominical de 13 de marzo de 1904125 .

Fecha de envio / Submission date: 12/07/2019

Fecha de aceptación / Acceptance date: 22/09/2019

Segunda parte: el debate politico-parlamentario", Revista del Trabajo, nums.61-62 (1982), pp.3591.

124 Juan Ignacio Palacio Morena, La institucionalización de la reforma social en España (18831924). La Comisión y el Instituto de Reformas Sociales, Madrid, 1988.

$125 \mathrm{M}^{\mathrm{a}}$ Jesús Espuny i Tomas, "El tiempo del trabajo: la ordenación histórica de una conquista laboral", Anuario de Historia del Derecho Español, 67 (1997), pp.1823-1841, o Luis Enrique de la Villa Gil, La formación histórica del derecho español del trabajo, Granada, 2003. 